\title{
Assessment of cleaning and disinfection in Salmonella- contaminated poultry layer houses using qualitative and semi-quantitative culture techniques
}

Andrew Wales, Mark Breslin, Robert Davies

Department of Food and Environmental Safety, Veterinary Laboratories Agency, Woodham Lane, New Haw, Addlestone, Surrey KT15 3NB, United Kingdom

Author for correspondence: Robert Davies

Telephone: 01932357361

Fax: $\quad 01932357595$

E-mail: r.h.davies@ vla.defra.gsi.gov.uk 


\section{ABSTRACT}

Salmonella infection of laying flocks in the UK is predominantly a problem of the persistent contamination of layer houses and associated wildlife vectors by $S$. Enteritidis. Methods for its control and elimination include effective cleaning and disinfection of layer houses between flocks, and it is important to be able to measure the success of such decontamination. A method for the environmental detection and semi-quantitative enumeration of salmonellae was used and compared with a standard qualitative method, in twelve Salmonella-contaminated caged layer houses before and after cleaning and disinfection. The quantitative technique proved to have comparable sensitivity to the standard method, and additionally provided insights into the numerical Salmonella challenge that replacement flocks would encounter. Elimination of $S$. Enteritidis was not achieved in any of the premises examined although substantial reductions in the prevalence and numbers of salmonellae were demonstrated, while in others an increase in contamination was observed after cleaning and disinfection. Particular problems with feeders and wildlife vectors were highlighted. The use of a quantitative method assisted the identification of problem areas, such as those with a high initial bacterial load or those experiencing only a modest reduction in bacterial count following decontamination.

\section{Keywords}

Salmonella, poultry, layers, eggs, chickens, environment, cleaning and disinfection 


\section{INTRODUCTION}

Salmonella enterica serovar Enteritidis came to prominence as a major food-borne pathogen in Europe and America during the 1980s (Hogue et al., 1997; Baumler et al., 2000). It is currently the serovar most commonly isolated from gastrointestinal Salmonella infections in the UK (Anon, 2005) and is amongst the most significant serovars in public health elsewhere, including North America (CDC, 2004). Poultry products, especially undercooked and raw eggs, have been a major risk factor for human infection with S. Enteritidis (Coyle et al., 1988; St Louis et al., 1988; Hogue et al., 1997; Palmer et al., 2000; CDC, 2004; De Buck et al., 2004).

Improved biosecurity and hygiene in the UK poultry industry and vaccination of the majority of commercial laying birds and broiler breeders, introduced in the mid to late 1990s, has been followed by a large reduction in reported incidents of $S$. Enteritidis in poultry and in humans (Anon, 2000). Breeder and multiplier flocks in the UK are generally free of Salmonella (Anon, 2004), as biosecurity and monitoring resources at this level in the production chain are considerable. However, the situation is different in production flocks and persistence of contamination on commercial laying farms is currently considered to be the predominant problem (van de Giessen et al., 1994; Davies and Breslin, 2003b). Cleaning and disinfection (C\&D) following depopulation of broiler and layer houses has been shown previously to have limited effectiveness in many cases (Davies and Wray, 1995, 1996; Davies et al., 1998; Davies and Breslin, 2003b) with technical issues, the choice of disinfectants and the influence of wildlife vectors being identified as significant factors.

Recently, a semi-quantitative most-probable-number technique has been evaluated for use in the monitoring of Salmonella in the poultry house environment (Wales et al., Semi-quantitative assessment of the distribution of Salmonella in the environment of caged layer flocks. J Appl. Microbiol. In press). The present report compares this method with an established qualitative method in the assessment of $C \& D$ in caged layer houses, and provides a comparison of the relative efficacies of differing $\mathrm{C} \& \mathrm{D}$ regimes. 


\section{MATERIALS AND METHODS}

\section{Sample collection}

The owners of caged layer flocks that had previously been identified through the Zoonoses Order Database, by personal contact, or through previous sampling, as having $S$. Enteritidis were approached. When permission for intensive sampling had been obtained, the flocks were visited and environmental samples were taken. At least two visits were made: once in late lay prior to depopulation and once following depopulation, cleaning and disinfection. One farm was also visited after cleaning but before disinfection. For standard qualitative culture (SS), samples were taken directly into $225 \mathrm{ml}$ of Buffered Peptone Water (BPW: Merck) using gauze surgical swabs (Kleenex Readiwipes: Robinson Healthcare). Samples consisted of approximately $25 \mathrm{~g}$ faecal material, floor spillage from under cages, dust from within and around cages (10 to $15 \mathrm{~g}$ ), surface swabs, rodent faeces ( 1 to10 g) and flies from adhesive paper or contact insecticidal traps ( 1 to $2 \mathrm{~g}$ ). Sterile swabs soaked in BPW were used to sample the surfaces $\left(0.5 \mathrm{~m}^{2}\right)$ of egg belts, spiral auger, chain or hopperfed feeder troughs, cleaned droppings boards and floors beneath cages, and to swab the interiors of empty cages and spillage cups or troughs beneath nipple lines, where composite samples were obtained from eight cages per swab. Similar sites were sampled for semi-quantitative culture (QS) on the same occasions. For this method, bulked faeces (approximately $30 \mathrm{~g}$ ) and dry environmental samples were collected into dry pots, and surface swabs from $0.1 \mathrm{~m}^{2}$ surface area of equipment were deposited in $90 \mathrm{ml}$ of chilled BPW.

All solid samples were returned to the laboratory under ambient conditions on the day of collection and processed immediately. Swab samples taken into BPW were kept in a cold box at below $10{ }^{\circ} \mathrm{C}$ and also processed on return to the laboratory. Mouse and rat carcasses were collected as available on four occasions and transported to the laboratory where the whole of the liver, spleen and intestines was removed aseptically and chopped with scissors for culture. 


\section{Standard culture technique}

Samples in BPW were pre-enriched at $37^{\circ} \mathrm{C}$ for $18 \mathrm{~h}$ and then cultured on selective and isolation media as for the QS technique. Representative Salmonella isolates were confirmed by complete serotyping at the Salmonella reference laboratory at VLA - Weybridge according to the Kaufmann-White Scheme (Popoff, 2001).

\section{Semi-quantitative culture technique}

Faeces $(10 \mathrm{~g})$ were weighed and mixed with $90 \mathrm{ml}$ BPW. A $10 \mathrm{ml}$ aliquot of this primary preparation was dispensed into a universal container to serve as the first in a series of ten-fold dilutions. The series was continued by taking $1 \mathrm{ml}$ from the primary preparation and mixing with $9 \mathrm{ml} \mathrm{BPW}$ and a decimal dilution series was completed by successively repeating this step five times, adding $1 \mathrm{ml}$ of each consequent dilution to $9 \mathrm{ml}$ BPW. Similarly, $10 \mathrm{~g}$ of other solid/dry samples (or less for fly and rodent viscera samples) was weighed and mixed with a ten-fold volume of BPW and dilution series in BPW were prepared. The BPW containing the surface swabs was vigorously agitated by shaking and stirring and serially diluted also.

For all samples a pre-enrichment incubation at $37^{\circ} \mathrm{C}$ for $18 \mathrm{~h}$ was performed on a series of dilutions comprising: the primary mixture in BPW ('0'), a separate $10 \mathrm{ml}$ aliquot of the same (' 1 '), plus the decimal dilutions (' 2 ' to ' 7 '). After incubation, $0.1 \mathrm{ml}$ of each of preparations ' 0 ' and ' 1 ' was inoculated onto modified semi-solid Rappaport-Vassiliadis agar with $0.01 \%$ novobiocin (MSRV; Difco 218681) and incubated at $41.5^{\circ} \mathrm{C}$ for 16 to $24 \mathrm{~h}$. Preparations ' 3 ' to ' 7 ' were refrigerated after incubation. Where opaque growth was seen on MSRV, a $1 \mu 1$ loop from the edge of the opaque growth zone was inoculated onto Rambach agar (Merck 107500). Which was incubated at $37{ }^{\circ} \mathrm{C} 24 \mathrm{~h}$. The plates were examined and any MSRV plates on which the growth had spread widely, but which were negative for Salmonella on the Rambach plates, were re-plated onto further Rambach agar after $48 \mathrm{~h}$ incubation of the MSRV. 
If Salmonella was isolated from either of the preparations ' 0 ' or ' 1 ' from any sample, then the dilution series ' 2 ' to '7' was cultured using the MSRV/Rambach method.

The likely density of Salmonella in a sample was quantified in tenfold bands by reference to the quantitative (QS) 'score', this being 1+ the designated number of the most dilute pre-enrichment broth that yielded a positive result.

For solid samples, the calculated relationship was:

Salmonella density $\left(\mathrm{cfu} \mathrm{g}^{-1}\right)=10^{(\mathrm{QS} \text { score-2) }}$ to $10^{(\mathrm{QS} \text { score-1) }}$

For swabs, the relationship was:

Salmonella density $\left(\mathrm{cfu} 0.1 \mathrm{~m}^{-2}\right)=10^{(\mathrm{QS} \text { score- } 1)}$ to $10^{\mathrm{QS} \text { score }}$

Where there was no growth in any dilution the QS score was zero and the Salmonella count was taken to be zero. 


\section{RESULTS}

\section{Effectiveness of cleaning and disinfection in layer houses}

Results are summarised in Tables 1 and 2. The effectiveness of C\&D varied widely between premises, and in none of the houses examined did C\&D result in no detectable Salmonella contamination. In some houses (particularly B and H) a high pre-depopulation (PD) prevalence of positive samples (46 to $93 \%$ ) was reduced to around $10 \%$, whereas in others (houses E, I, J) the reduction achieved was more modest. By contrast, an increase rather than a reduction in prevalence and in mean quantitative score was recorded post-C\&D in several instances (houses A, D, F, G). Considering the QS method data, overall increases in the prevalence of positive samples following C\&D were paralleled by increases in the quantitative mean scores, and similarly with decreases postC\&D. When the methods of C\&D are compared (Table 2), it appears that greater decreases in Salmonella contamination were associated with initial dry cleaning, moderate to low residual organic material, and the use of aldehydes (formaldehyde or formaldehyde/glutaraldehyde combinations) for disinfection and/or fogging. Increased contamination post-C\&D correlated with wet initial cleaning to a poor standard. Exceptions to this pattern were: house A with increases in the prevalence of positive samples and in mean overall QS score post-C\&D despite dry cleaning, a low organic residue and formaldehyde fogging; and house K where a substantial reduction in Salmonella was recorded despite a high level of residual organic material. In house $\mathbf{J}$, where sampling was performed additionally between the cleaning and disinfection phases, the greatest reduction in Salmonella contamination was associated with dry cleaning, and indeed there was an apparent increase detected by the QS method following disinfection with a peroxygen disinfectant. 


\section{Effect of cleaning and disinfection by location}

For each location where paired pre- and post-C\&D sampling was performed, the qualitative data for SS and QS methods is illustrated in Figure 1, grouped by locations in the layer houses. The data for the cages relates to dust sampled around the cages pre-depopulation and swabs from within the cages post-C\&D. The proportion of feeder sites showing an increase in the prevalence of positive samples post-C\&D was 7/13 (54\%), whereas the equivalent percentages for faeces/droppings boards, floors and egg belt swabs were lower, at $33 \%, 19 \%$ and $14 \%$ respectively. This relatively poor effect of $C \& D$ upon feeders was seen strongly in the semi-quantitative data when changes in mean and maximum QS scores are considered between locations (Figure 2).

Due to difficulty of access to occupied cages in the populated henhouses, there is no predepopulation data on the contamination of drinkers. However, the post-C\&D data show a substantial residual level of Salmonella contamination of drinkers, amounting to $30 \%$ (SS) and $37 \%$ (QS) of all samples examined, with mean QS scores ranging from zero to 2.2.

\section{Wildlife vectors}

Table 3 details the findings from potential wildlife vectors. There was a high prevalence of positive samples amongst rodent faeces, and a high quantitative score from one of the two fly samples subjected to the QS method. Indeed, the mean score from flies in house J pre-depopulation was, at 5.2, the second highest in the entire data set, despite four of the 11 samples having a score of zero.

\section{Comparison of qualitative and semi-quantitative methods}

Both standard and semi-quantitative methods generated a proportion of positive samples (prevalence) figure for each location sampled. The change in this prevalence following C\&D is shown for each method and location in Figure 1. The two detection techniques showed a change in 
the same direction in $15 / 16$ cases (the exception being the feeders in house $\mathrm{J}$ ), and the percentage changes generally were of similar magnitude. Samples from the floors had the most complete data for comparison between the two techniques, and these showed that the magnitude of individual prevalence values, as well as the change observed with C\&D, was similar for both SS and QS methods. There is, however, less agreement between the prevalence data for the two techniques when pooled results from each house are compared (tables 1 and 2).

A comparison between changes in QS-generated prevalences and changes in quantitative scores is shown in Figure 3, for locations where paired pre- and post-C\&D data is available. The direction of change following C\&D for prevalence and mean scores was the same at each location, i.e. there were no locations where the prevalence increased and the mean score decreased, or vice versa. However, the maximum score changed in the opposite direction to the prevalence in $3 / 32$ cases. There was no apparent correlation between the magnitudes of change in prevalence and in mean QS score, as in many instances large changes in one were accompanied by small changes in the other at the same location. House G showed especially marked shifts in QS mean scores compared with prevalence changes but, apart from this, particular patterns were not evident between prevalence and score changes when the data was considered on a house-by-house or location-by-location basis.

Relationships between changes in mean and maximum quantitative scores (most minimum scores were zero) are shown in Figure 2, ordered by location and the magnitude of the change in mean floor score following C\&D. (Faeces, cages and drinkers had little paired pre- and post-C\&D semi-quantitative data and are, consequently, omitted.) In all cases except one (feeder, house F) the change in maximum score was in the same direction as that in mean score. The change in score at any one location did not appear to correlate with changes in score at other locations in the same house. In particular, whereas only two of 11 farms showed an increase in mean score for floor spillage/swabs, six of 11 showed an increase in score for feeders, of up to 2 units for mean and 4 units for maximum score. 


\section{DISCUSSION}

The aim of cleaning and disinfection of poultry houses should be to eliminate contamination of the building and equipment by pathogenic micro-organisms and by organic matter that can harbour such organisms following repopulation. There are clearly many technical difficulties with achieving this aim, as shown in the present study where no house was rendered free of detectable Salmonella. Indeed, in many cases the apparent degree of Salmonella contamination increased after C\&D. Some obstacles, such as access to parts of layer cages, the difficulty of sealing ventilation systems and restrictions on the use of phenolic disinfectants due to egg taint, are difficult to overcome and probably contribute to a lower apparent effectiveness of $C \& D$ in caged layer houses when compared with broiler and breeder accommodation (Davies et al., 2001; Davies and Breslin, 2003b). However, the present study shows a wide range of effectiveness of C\&D between premises, suggesting that certain more easily controllable factors can have a significant impact.

The amount of organic residue left after cleaning would be expected to correlate with overall reductions in Salmonella contamination, and indeed there is evidence for this in the present data. Wet cleaning, which might be thought to be more effective than dry cleaning in the removal of debris, was in fact consistently only moderately effective, and was associated with a poorer overall outcome. Wet cleaning may cause increased mobilisation and activation of Salmonella (Davies and Wray, 1995), and bacteria in wet matter may benefit from increased protection against penetration by disinfectants unless there is a drying stage between washing and disinfection. In houses A, B and C, dry cleaning achieved low levels of residual organic matter, and whilst this should also be achievable with wet cleaning, it is clear that both techniques need to be performed diligently to be effective, and that excessive residual material will interfere with disinfection (Tenk et al., 1996; Knape et al., 2001). 
The findings in respect of the disinfectants used are substantially in agreement with previous reports on the relative effectiveness of aldehydes, peroxygens, quaternary ammonium compounds and phenolics (Davies and Wray, 1995; Berchieri and Barrow, 1996; McDonnell and Russell, 1999). Aldehydes, active in the presence of substantial organic residue, were associated with the larger reductions in Salmonella. House A is an exception, having a poor outcome despite dry cleaning, low residue and formaldehyde treatment, but in this case the distribution of formaldehyde was insufficient because of the large size of the house. Whilst there is a limited amount of interpretation possible with an uncontrolled study such as the present one, such exceptions reinforce the point that effective C\&D is typically dependent upon rigorous attention to detail (Davies and Wray, 1996) and that careful assessment is needed to identify weaknesses in the procedure. Formalinised Steam treatment, as practised in Denmark (Gradel et al., 2003), potentially could offer further scope for improvement, but at a considerably increased cost.

When both qualitative and semi-quantitative data are considered on a location-by-location basis, it appears that $C \& D$ is effective to differing extents at the various locations within layer houses. In particular, feeders show poorer results, with six out of 10 houses showing an increase in the quantitative score, and only two showing a decrease. It is likely that poor removal of feed, which can act as a bacterial nutrient after washing or ineffective disinfection, or difficulty with access to internal surfaces and components of feeders are factors and the increases seen, of up to four log units in the maximum score, are of particular note. The failure to achieve good decontamination of equipment such as feeders and drinkers is likely to lead to early re-exposure of new flocks to Salmonella.

Comparisons between the qualitative results of SS and QS methods at individual locations shows reasonable agreement between the techniques, consistent with a previous study (Wales et al., Semi-quantitative assessment of the distribution of Salmonella in the environment of caged layer flocks. J Appl. Microbiol. In press). Overall percentage reductions (or increases) for the two methods 
at each house show less correlation (Table 2). However, the contribution by each location to the overall percentage value for each house varied between SS and QS methods. For example, there was relatively more post-C\&D data from faeces and droppings boards with the SS technique, and relatively more pre-depopulation egg belt swab data with the QS method. This, plus the fact that the pooled data is not paired for pre- and post-C\&D samples as is the case for the location-specific data in Figure 1, will tend to generate more variation in 'overall' percentages.

The potential added value of using a semi-quantitative method of Salmonella detection includes the ability to estimate the likely numerical bacterial challenge to a new flock from various sources. Treatment of large flocks of birds by vaccination and/or competitive exclusion treatments has limitations in the face of substantial environmental challenge and repeated laying flock infections occur in most cases when previously infected cage layer houses are restocked (Davies and Breslin, 2003a, b, 2004). Semi-quantitative data could help to target and evaluate reductions in the level of such challenge. Specifically, in the present study, whilst the issue of ineffective cleaning of feeders is evident in the qualitative data, it is strongly reinforced by the semi-quantitative data which shows a substantial increase in maximum scores with $C \& D$ as already discussed. There is a further example of the value of quantitative scores in the wildlife vector data, where mouse viscera and fly samples returned the two highest mean scores in the data set, of 7 and 5.2 respectively, despite more modest prevalence values of $1 / 3$ and $7 / 11$, demonstrating the variability of infection and possibility of amplification of Salmonella numbers in wildlife vectors. The importance of wildlife vectors has been highlighted previously (Guard-Petter, 2001; Davies and Breslin, 2001; Mian et al., 2002; Garber et al., 2003) and effective control of these appears to be essential to avoid persistent infection on cage layer farms.

There is no strong correlation at any site between prevalence and quantitative score, either for values (Table 1) or for changes in values (Table 2, Figure 3). It is possible that the small-scale distribution of organisms may be significant in this regard, with an even but sparse distribution 
yielding high prevalences but low maximum QS scores, and a multifocal concentration pattern giving a lower prevalence but higher maximum QS scores. Factors potentially affecting such distributions include the physical nature of the substrate, the micro-environment (humidity, nutrients, free water, etc.), disruptive forces such as air currents and movement of scrapers and belts, and discrete carriers such as mouse faecal pellets and flies. In view of these considerations, the most comprehensive assessments of house contamination would make use of both types of data. 'Standard' qualitative sampling can achieve wide coverage at a lower cost than could a quantitative method, but prevalence data alone may be less successful than the latter approach at identifying areas of high bacterial load. The routine use of a semi-quantitative method would only be economically feasible if a high degree of pooling was applied or by using a more limited range of dilutions to identify high and low level contamination, and it may be that the best use of such a technique is as a research tool, to inform more widely the targeting of sampling and cleaning,

\section{CONCLUSIONS}

Cleaning and disinfection typically does not achieve the elimination of Salmonella from caged layer houses. Currently, thorough cleaning followed by a formaldehyde based disinfectant appears to offer the best reduction in contamination with the techniques currently available in the UK, but the manner of application of the chosen techniques is of major importance in maximising reductions in contamination. However, if wildlife vectors are not strictly controlled, these are likely to negate even the most effective $C \& D$ regimes. Use of a semi-quantitative detection method allows more discriminatory examination of the effectiveness of $C \& D$ and the likely challenge to new flocks, and helps to highlight the importance of particular elements, for example wildlife vectors. 


\section{ACKNOWLEDGEMENTS}

This work was funded by Defra. The authors would like to thank farmers and their staff as well as VLA laboratory staff for their invaluable assistance with this study. 


\section{REFERENCES}

Anon 2000. Salmonella in Livestock Production in GB 1999. Weybridge, UK, Veterinary

Laboratories Agency.

Anon 2004. Salmonella in Livestock Production in GB 2003. Weybridge, UK, Veterinary

Laboratories Agency.

Anon 2005. Trends in selected gastrointestinal infections - 2004. The Communicable Disease Report

Weekly v15, number 14. http://www.hpa.org.uk/cdr/archives/2005/cdr1405.pdf Accession date 30/09/05.

Baumler, A.J., Hargis, B.M., Tsolis, R.M., 2000, Tracing the origins of Salmonella outbreaks. Science 287, 50-52.

Berchieri, A., Barrow, P.A., 1996, The antibacterial effects for Salmonella Enteritidis phage type 4 of different chemical disinfectants and cleaning agents tested under different conditions. Avian Pathology 25, 663-673.

CDC 2004. Salmonella Surveillance: Annual Summary, 2003 (Atlanta, Georgia, Centers for Disease Control and Prevention, US Department of Health and Human Services), p. 89.

Coyle, E.F., Palmer, S.R., Ribeiro, C.D., Jones, H.I., Howard, A.J., Ward, L., Rowe, B., 1988, Salmonella enteritidis phage type 4 infection: association with hen's eggs. Lancet 2, 12951297.

Davies, R., Breslin, M., 2001, Environmental contamination and detection of Salmonella enterica serovar Enteritidis in laying flocks. Vet. Rec. 149, 699-704.

Davies, R., Breslin, M., 2003a, Effects of vaccination and other preventive methods for Salmonella enteritidis on commercial laying chicken farms. Vet. Rec. 153, 673-677.

Davies, R., Breslin, M., 2003b, Observations on Salmonella contamination of commercial laying farms before and after cleaning and disinfection. Vet. Rec. 152, 283-287. 
Davies, R., Breslin, M., 2004, Observations on Salmonella contamination of eggs from infected commercial laying flocks where vaccination for Salmonella enterica serovar Enteritidis had been used. Avian Pathol 33, 135-146.

Davies, R.H., Wray, C., 1995, Observations on disinfection regimens used on Salmonella-Enteritidis infected poultry units. Poult. Sci. 74, 638-647.

Davies, R.H., Wray, C., 1996, Studies of contamination of three broiler breeder houses with Salmonella Enteritidis before and after cleansing and disinfection. Avian Dis. 40, 626-633.

Davies, R.H., Bedford, S., Wray, C., 1998. A semi-quantitative study of the effectiveness of disinfection of broiler breeder houses contaminated with Salmonella. In: 4th World Congress on Foodborne Infections and Intoxications, Berlin, pp. 414-424.

Davies, R., Breslin, M., Corry, J.E., Hudson, W., Allen, V.M., 2001, Observations on the distribution and control of Salmonella species in two integrated broiler companies. Vet. Rec. 149, 227 232.

De Buck, J., Van Immerseel, F., Haesebrouck, F., Ducatelle, R., 2004, Colonization of the chicken reproductive tract and egg contamination by Salmonella. J. Appl. Microbiol. 97, 233-245.

Garber, L., Smeltzer, M., Fedorka-Cray, P., Ladely, S., Ferris, K., 2003, Salmonella enterica Serotype enteritidis in table egg layer house environments and in mice in US layer houses and associated risk factors. Avian Dis. 47, 134-142.

Gradel, K.O., Jorgensen, J.C., Andersen, J.S., Corry, J.E., 2004, Monitoring the efficacy of steam and formaldehyde treatment of naturally Salmonella-infected layer houses. J. Appl. Microbiol. 96, 613-622.

Guard-Petter, J., 2001, The chicken, the egg and Salmonella enteritidis. Environ Microbiol 3, 421430.

Hogue, A., White, P., Guard-Petter, J., Schlosser, W., Gast, R., Ebel, E., Farrar, J., Gomez, T., Madden, J., Madison, M., McNamara, A.M., Morales, R., Parham, D., Sparling, P., Sutherlin, 
W., Swerdlow, D., 1997, Epidemiology and control of egg-associated Salmonella enteritidis in the United States of America. Rev. Sci. Tech. 16, 542-553.

Knape, K.D., Carey, J.B., Ricke, S.C., 2001, Response of foodborne Salmonella spp. marker strains inoculated on egg shell surfaces to disinfectants in a commercial egg washer. Journal of Environmental Science and Health Part B-Pesticides Food Contaminants and Agricultural Wastes 36, 219-227.

McDonnell, G., Russell, A.D., 1999, Antiseptics and disinfectants: Activity, action, and resistance. Clin. Microbiol. Rev. 12, 147-179.

Mian, L.S., Maag, H., Tacal, J.V., 2002, Isolation of Salmonella from muscoid flies at commercial animal establishments in San Bernardino County, California. J. Vector Ecol. 27, 82-85.

Palmer, S., Parry, S., Perry, D., Smith, R., Evans, M., Nehaul, L., Roberts, R., Walapu, M., Wright, D., 2000, The role of outbreaks in developing food safety policy: population based surveillance of Salmonella outbreaks in Wales 1986-98. Epidemiol. Infect. 125, 467-472.

Popoff, M.Y., 2001, Antigenic formulas of the Salmonella serovars, 8th Edition Edition. WHO Collaborating Centre for Reference and Research on Salmonella. Institut Pasteur, Paris.

St Louis, M.E., Morse, D.L., Potter, M.E., DeMelfi, T.M., Guzewich, J.J., Tauxe, R.V., Blake, P.A., 1988, The emergence of grade A eggs as a major source of Salmonella enteritidis infections. New implications for the control of salmonellosis. JAMA 259, 2103-2107.

Tenk, I., Kostyak, A., Matray, D., 1996, Observations on the efficacy of the temporary preventive disinfection of poultry houses with special reference to the presence of Salmonellae. Magyar Allatorvosok Lapja 51, 614-616.

van de Giessen, A.W., Ament, A.J., Notermans, S.H., 1994, Intervention strategies for Salmonella enteritidis in poultry flocks: a basic approach. Int. J. Food Microbiol. 21, 145-154. 


\section{TABLES}

Table 1: Summarised qualitative and semi-quantitative (QS score) data before and after cleaning and disinfection for all locations

\begin{tabular}{|c|c|c|c|c|c|c|c|}
\hline \multirow{2}{*}{$\begin{array}{l}\text { Farm/ } \\
\text { Flock } \\
\text { (label) }\end{array}$} & \multirow[t]{2}{*}{ Stage* } & \multicolumn{2}{|l|}{ SS method } & \multicolumn{4}{|l|}{ QS method } \\
\hline & & $\begin{array}{l}\text { proportion } \\
\text { positive }\end{array}$ & $\begin{array}{l}\text { percent } \\
\text { positive }\end{array}$ & $\begin{array}{l}\text { proportion } \\
\text { positive }\end{array}$ & $\begin{array}{l}\text { percent } \\
\text { positive }\end{array}$ & $\begin{array}{l}\text { mean QS } \\
\text { score }^{\dagger}\end{array}$ & $\begin{array}{l}\text { range QS } \\
\text { scores }^{\dagger}\end{array}$ \\
\hline \multirow{2}{*}{$\begin{array}{l}\text { CK } 11 / 3 \\
\text { (A) }\end{array}$} & $\mathrm{BD}$ & $9 / 15$ & 60 & $4 / 20$ & 20 & 0.20 & $0-2$ \\
\hline & PCD & $17 / 40$ & 43 & $13 / 24$ & 54 & 0.92 & $0-4$ \\
\hline \multirow{2}{*}{$\begin{array}{l}\mathrm{CC} 3 / 3 \\
\text { (B) }\end{array}$} & $\mathrm{BD}$ & $28 / 30$ & 93 & $16 / 25$ & 64 & 1.50 & $0-7$ \\
\hline & PCD & $6 / 58$ & 10 & $2 / 25$ & 8 & 0.08 & $0-1$ \\
\hline \multirow{2}{*}{$\begin{array}{l}\text { CT3/8 } \\
\text { (C) }\end{array}$} & $\mathrm{BD}$ & $124 / 151$ & 82 & $1 / 1$ & 100 & 3.00 & $0-3$ \\
\hline & PCD & $22 / 126$ & 18 & $4 / 18$ & 22 & 0.57 & $0-4$ \\
\hline \multirow{2}{*}{$\begin{array}{l}\text { CT4/3 } \\
\text { (D) }\end{array}$} & $\mathrm{BD}$ & $6 / 25$ & 24 & $0 / 20$ & 0 & 0.00 & \\
\hline & PCD & $29 / 56$ & 52 & $9 / 25$ & 36 & 0.27 & $0-1$ \\
\hline \multirow{2}{*}{$\begin{array}{l}\text { CT5/4 } \\
\text { (E) }\end{array}$} & BD & $17 / 30$ & 57 & $18 / 29$ & 62 & 1.12 & $0-5$ \\
\hline & PCD & $7 / 28$ & 25 & $5 / 25$ & 20 & 0.32 & $0-2$ \\
\hline \multirow{2}{*}{$\begin{array}{l}\text { CT6/2 } \\
(\mathrm{F})\end{array}$} & $\mathrm{BD}$ & $12 / 21$ & 57 & $10 / 20$ & 50 & 1.15 & $0-5$ \\
\hline & PCD & $33 / 40$ & 83 & $22 / 30$ & 73 & 1.20 & $0-4$ \\
\hline \multirow{2}{*}{$\begin{array}{l}\text { CT6/5 } \\
\text { (G) }\end{array}$} & $\mathrm{BD}$ & $17 / 21$ & 81 & $16 / 20$ & 80 & 1.70 & $0-6$ \\
\hline & PCD & $38 / 40$ & 95 & $26 / 30$ & 87 & 1.82 & $0-4$ \\
\hline \multirow{2}{*}{$\begin{array}{l}\text { CT9/8 } \\
\text { (H) }\end{array}$} & $\mathrm{BD}$ & $14 / 30$ & 47 & $10 / 15$ & 67 & 1.20 & $0-4$ \\
\hline & PCD & $3 / 40$ & 8 & $1 / 25$ & 4 & 0.04 & $0-1$ \\
\hline \multirow{2}{*}{$\begin{array}{l}\mathrm{HM} 1 / 2 \\
\text { (I) }\end{array}$} & $\mathrm{BD}$ & $5 / 6$ & 83 & $18 / 20$ & 90 & 2.90 & $0-7$ \\
\hline & PCD & $21 / 30$ & 70 & $13 / 25$ & 52 & 1.16 & $0-5$ \\
\hline \multirow{3}{*}{$\begin{array}{l}\mathrm{HM} 3 / 4 \\
(\mathrm{~J})\end{array}$} & BD & $47 / 68$ & 69 & $17 / 20$ & 85 & 2.35 & $0-5$ \\
\hline & PC & $20 / 40$ & 50 & $6 / 30$ & 20 & 0.44 & $0-5$ \\
\hline & PD & $12 / 30$ & 40 & $16 / 30$ & 53 & 0.88 & $0-4$ \\
\hline \multirow{2}{*}{$\begin{array}{l}\text { HM7/3 } \\
(\mathrm{K})\end{array}$} & BD & $11 / 32$ & 34 & $4 / 20$ & 20 & 0.65 & $0-4$ \\
\hline & PCD & $4 / 40$ & 10 & $3 / 30$ & 10 & 0.12 & $0-1$ \\
\hline \multirow{2}{*}{$\begin{array}{l}\text { SG8/B } \\
\text { (L) }\end{array}$} & BD & $18 / 42$ & 43 & $8 / 20$ & 40 & 1.05 & $0-4$ \\
\hline & PCD & $4 / 30$ & 13 & $1 / 30$ & 3 & 0.04 & $0-2$ \\
\hline
\end{tabular}

Proportion figures for SS and QS methods indicate the overall number of positive samples compared with the total number of samples taken. * 'BD' Before depopulation; 'PCD' Post cleaning and disinfection; 'PC' Post-cleaning; 'PD' Post-disinfection. ${ }^{\dagger}$ Arithmetical mean and range of QS scores. For solids (faeces, floor spillage), QS score conversions to Salmonella per gram are: ' 0 ' - 0 ; ' 1 ' - $<1$; ' 2 ' - 1 to 10 ; ' 3 ' - 10 to $10^{2}$; ' 4 ' - $10^{2}$ to $10^{3}$; ' 5 ' - $10^{3}$ to $10^{4}$; ' 6 ' - $10^{4}$ to $10^{5}$; ' 7 ' $-10^{5}$ to $10^{6}$. For swabs, conversions to Salmonella per $0.1 \mathrm{~m}^{2}$ are: ' 0 ' - 0 , ' 1 ' - 1 to 10 ; ' 2 ' - 10 to $10^{2}$; ' 3 ' - $10^{2}$ to $10^{3}$; ' 4 ' - $10^{3}$ to $10^{4} ;$ ' 5 ' - $10^{4}$ to $10^{5} ;$ ' 6 ' - $10^{5}$ to $10^{6}$. 
Table 2: Overall Salmonella contamination data plus details of cleaning, disinfection and isolates

\begin{tabular}{|c|c|c|c|c|c|c|}
\hline \multirow[t]{2}{*}{ Flock* } & \multicolumn{2}{|c|}{$\begin{array}{l}\text { Change in percent } \\
\text { positive with } C \& D\end{array}$} & \multirow{2}{*}{$\begin{array}{l}\text { Change in } \\
\text { mean QS } \\
\text { score with } \\
\text { C\&D }\end{array}$} & \multirow{2}{*}{$\begin{array}{l}\text { Cleaning and disinfection }(C \& D) \\
\text { 1. Initial clean } \\
\text { 2. Type of disinfectant } \\
\text { 3. Final fog application }\end{array}$} & \multirow{2}{*}{$\begin{array}{l}\text { Organic } \\
\text { residue } \\
\text { after } \\
\text { cleaning }\end{array}$} & \multirow[t]{2}{*}{$\begin{array}{l}\text { S. Enteritidis phagetypes (PT) and } \\
\text { other Salmonella serovars isolated }\end{array}$} \\
\hline & SS & QS & & & & \\
\hline A & -17.5 & 34.2 & 0.72 & $\begin{array}{l}\text { 1. Dry clean } 2 \text {. Peroxygen } \\
\text { 3. Formaldehyde fog }\end{array}$ & Low & PT $6,35,21 \mathrm{~B}(\mathrm{BD} / \mathrm{PCD})$ \\
\hline B & -83.0 & -56.0 & -1.42 & $\begin{array}{l}\text { 1. Dry clean 2. Glutaraldehyde/ } \\
\text { quaternary } \mathrm{NH}_{4}^{+} \text {compound }\end{array}$ & Low & $\begin{array}{l}\text { PT 4, } 6 \text { (BD) } \\
\text { PT } 6 \text { (PCD) }\end{array}$ \\
\hline $\mathrm{C}$ & -64.6 & -77.8 & -2.43 & $\begin{array}{l}\text { 1. Dry clean } \\
\text { 3. Formaldehyde fog }\end{array}$ & Low & $\begin{array}{l}\text { PT 4, 6; Indiana, Mbandaka (BD) } \\
\text { PT 4, } 6 \text { (PCD) }\end{array}$ \\
\hline $\mathrm{D}$ & 27.8 & 36.0 & 0.27 & $\begin{array}{l}\text { 1. Wet clean - quaternary } \\
\text { detergent } 2 \text {. Peroxygen }\end{array}$ & Moderate & $\begin{array}{l}\text { PT } 6(\mathrm{BD}) \\
\text { PT } 6 ; \text { Indiana }(\mathrm{PCD})\end{array}$ \\
\hline $\mathrm{E}$ & -31.7 & -42.1 & -0.80 & $\begin{array}{l}\text { 1. Wet clean - quaternary } \\
\text { detergent } 2 \text {. Peroxygen }\end{array}$ & Moderate & PT 6 (BD/PCD) \\
\hline $\mathrm{F}$ & 25.4 & 23.3 & 0.05 & $\begin{array}{l}\text { 1. Wet clean - quaternary } \\
\text { detergent } 2 \text {. Peroxygen }\end{array}$ & Moderate & PT 6 (BD/PCD) \\
\hline $\mathrm{G}$ & 14.0 & 6.7 & 0.12 & $\begin{array}{l}\text { 1. Wet clean - quaternary } \\
\text { detergent } 2 \text {. Peroxygen }\end{array}$ & Moderate & $\begin{array}{l}\text { PT } 6 \text { (BD) } \\
\text { PT } 6 \text { (PCD) }\end{array}$ \\
\hline $\mathrm{H}$ & -39.2 & -62.7 & -1.16 & $\begin{array}{l}\text { 1. Dry clean } \\
\text { 3. Formaldehyde fog }\end{array}$ & Moderate & PT 6, 4, 7 (BD/PCD) \\
\hline I & -13.3 & -38.0 & -1.74 & $\begin{array}{l}\text { 1. Dry clean } \\
\text { 2. Peroxygen }\end{array}$ & High & $\begin{array}{l}\text { Enteritidis, not phage-typed (BD) } \\
\text { PT } 4,7 \text {; Agona (PCD) }\end{array}$ \\
\hline $\mathbf{J}$ & $\begin{array}{l}-19.1^{\dagger} \\
-10.0^{\ddagger}\end{array}$ & $\begin{array}{r}-65.0^{\dagger} \\
33.3^{\ddagger}\end{array}$ & $\begin{array}{c}-1.91^{\dagger} \\
0.44^{\ddagger}\end{array}$ & $\begin{array}{l}\text { 1. Dry clean } \\
\text { 2. Peroxygen }\end{array}$ & High & $\begin{array}{l}\text { PT 4, 7, 35; Cubana (BD) } \\
\text { PT 4, 7, } 35 \text { (PC/PD) }\end{array}$ \\
\hline $\mathrm{K}$ & -24.4 & -10.0 & -0.53 & $\begin{array}{l}\text { 1. Dry clean } \\
\text { 2. Glutaraldehyde/formaldehyde }\end{array}$ & High & $\begin{array}{l}\text { PT } 4 \text { (BD) } \\
\text { PT } 4 \text { (PCD) }\end{array}$ \\
\hline $\mathrm{L}$ & -29.6 & -36.7 & -1.01 & $\begin{array}{l}\text { 1. Dry clean 2. Tar oil phenolic } \\
\text { 3. Formaldehyde fog }\end{array}$ & Moderate & $\begin{array}{l}\text { PT } 4,7 \text { (BD) } \\
\text { PT } 4 \text { (PCD) }\end{array}$ \\
\hline
\end{tabular}

Values indicate the change in percentage of positive samples, or the change in the arithmetical mean QS score, following cleaning and disinfection. *Labels as given in Table $1 .{ }^{\dagger}$ Change following cleaning only. ${ }^{\star}$ Change from cleaned to cleaned and disinfected states. '`BD' - Before depopulation. 'PCD' - Post cleaning and disinfection. 'PC' - Post-cleaning. 'PD' Post-disinfection. 
Table 3: Isolations of Salmonella Enteritidis from wildlife vectors

\begin{tabular}{|c|c|c|c|c|c|c|}
\hline Flock* & Stage $^{\dagger}$ & Mouse viscera & Mouse faeces & Rat viscera & Rat faeces & Flies \\
\hline $\mathrm{C}$ & $\begin{array}{l}\mathrm{BD} \\
\mathrm{PCD}\end{array}$ & $1 / 1$ & $\begin{array}{l}1 / 1 \\
0 / 2\end{array}$ & & $1 / 1$ & \\
\hline $\mathrm{D}$ & $\begin{array}{l}\mathrm{BD} \\
\mathrm{PCD}\end{array}$ & & & & $\begin{array}{l}1 / 1 \\
4 / 4\end{array}$ & \\
\hline $\mathrm{E}$ & PCD & & & & $2 / 2$ & \\
\hline G & PCD & & & $1 / 2 ; 2.5(0-5)$ & $2 / 2$ & \\
\hline I & PCD & & $4 / 4 ; 2.2(1-4)$ & & & \\
\hline $\mathrm{J}$ & $\begin{array}{l}\text { BD } \\
\text { PC } \\
\text { PD }\end{array}$ & $\begin{array}{l}1 / 3 ; 7 \\
1 / 2 ; 4\end{array}$ & $\begin{array}{l}2 / 2^{\S} \\
4 / 6 ; 1.0(1-2)\end{array}$ & & & $\begin{array}{l}7 / 11 ; 5.2(0-7)^{\S} \\
3 / 5 ; 1.2(1-3)\end{array}$ \\
\hline $\mathrm{K}$ & $\mathrm{BD}$ & & $0 / 4$ & & & \\
\hline $\mathrm{L}$ & $\mathrm{BD}$ & & & & $6 / 11$ & $1 / 1$ \\
\hline
\end{tabular}

Values are: proportion of positive samples (SS method), proportion of positive samples; mean (range) QS score (QS method). * Flock identities are as given in Table 1. ' ${ }^{\dagger}$ BD' - Before depopulation. 'PCD' - Post cleaning and disinfection. 'PC' Post-cleaning. 'PD' Post-disinfection. ${ }^{\S}$ Data published previously (Wales et al., J Appl. Microbiol. In press). 


\section{FIGURES}

Figure 1: Effect of cleaning and disinfection upon the percentage of samples positive for Salmonella

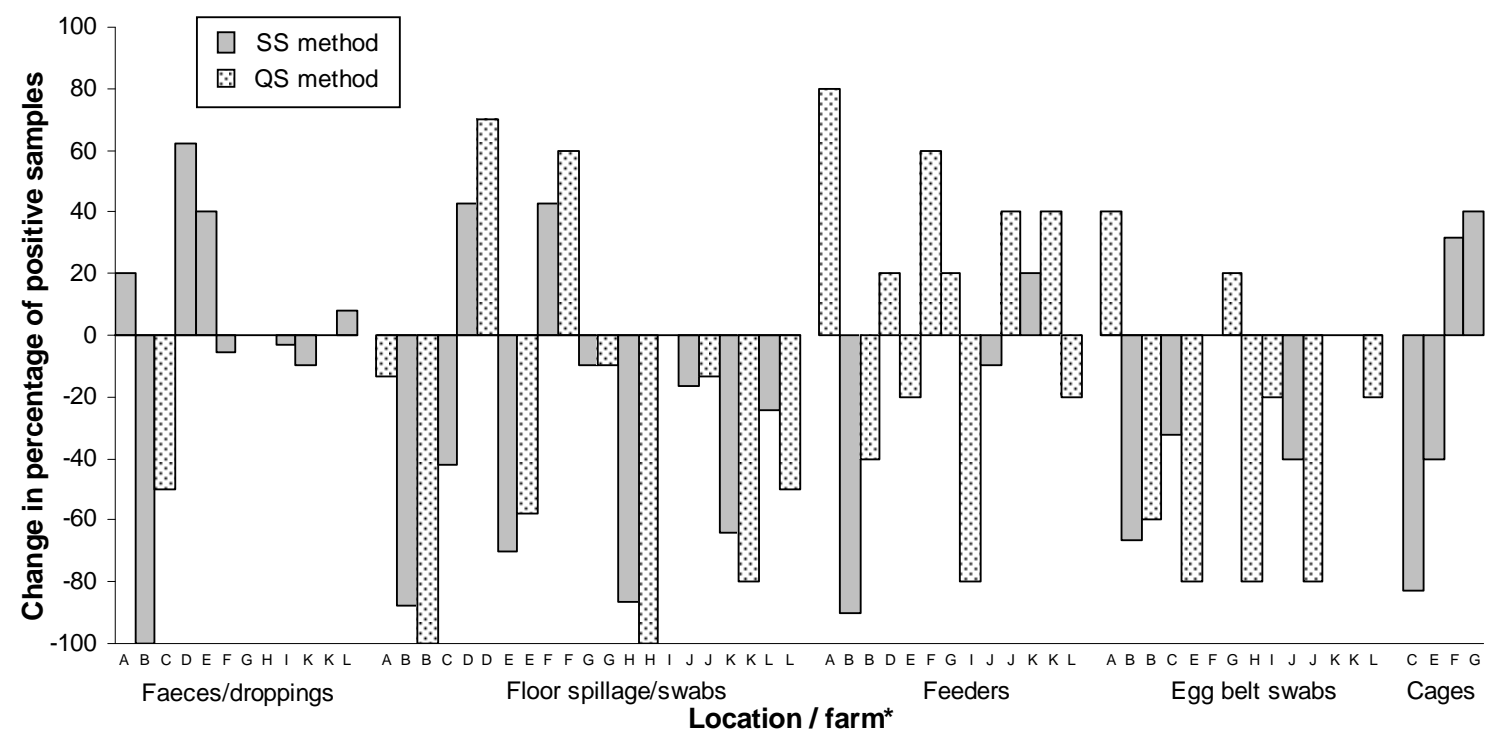

* Farms are lettered as shown in Table 1 
Figure 2: Effect of cleaning and disinfection upon mean and maximum quantitative scores for Salmonella

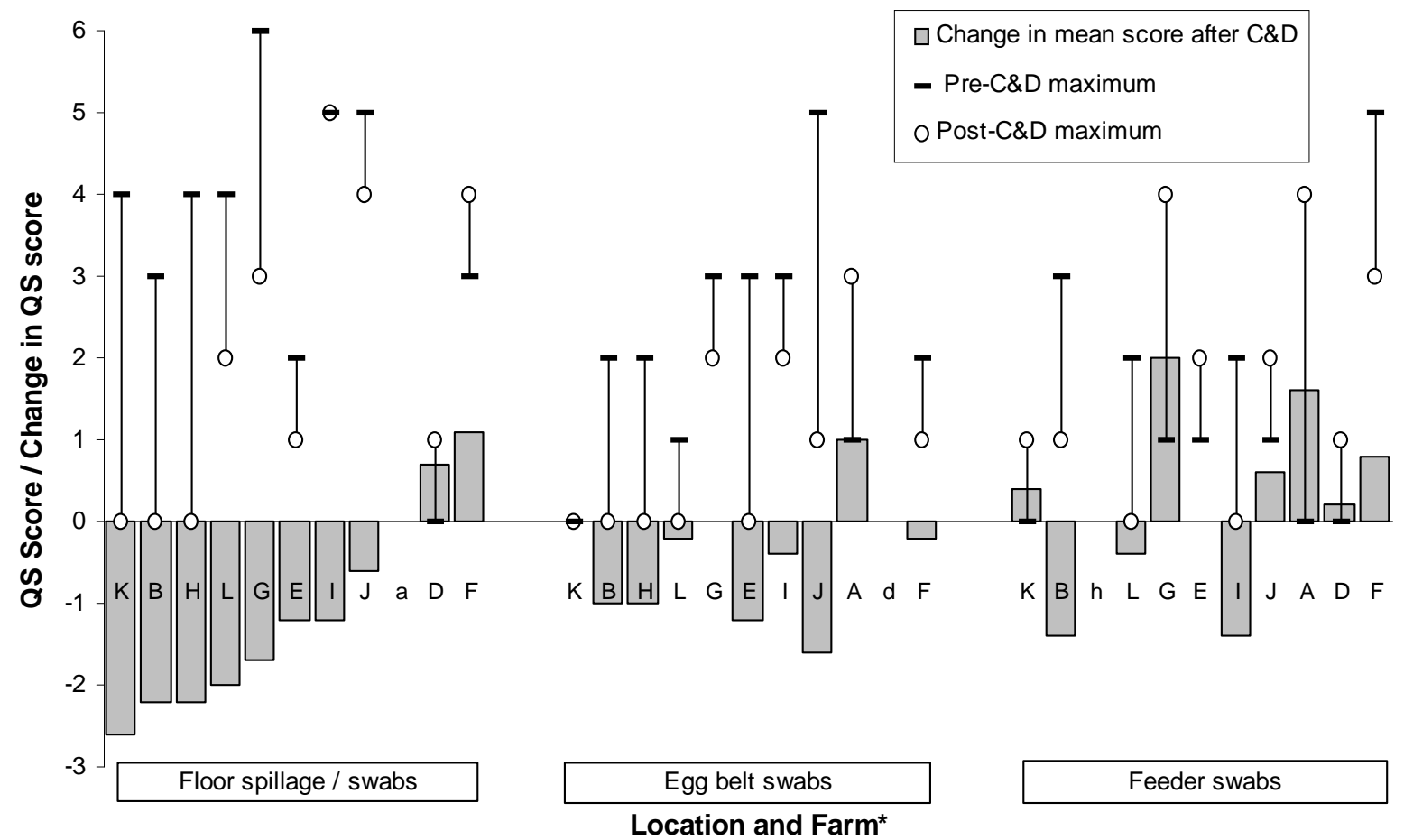

Farms are lettered as shown in Table 1. Lower-case letters indicate no data available for that location. 
Figure 3: Comparison of qualitative and semi-quantitative data showing the effect of cleaning and disinfection

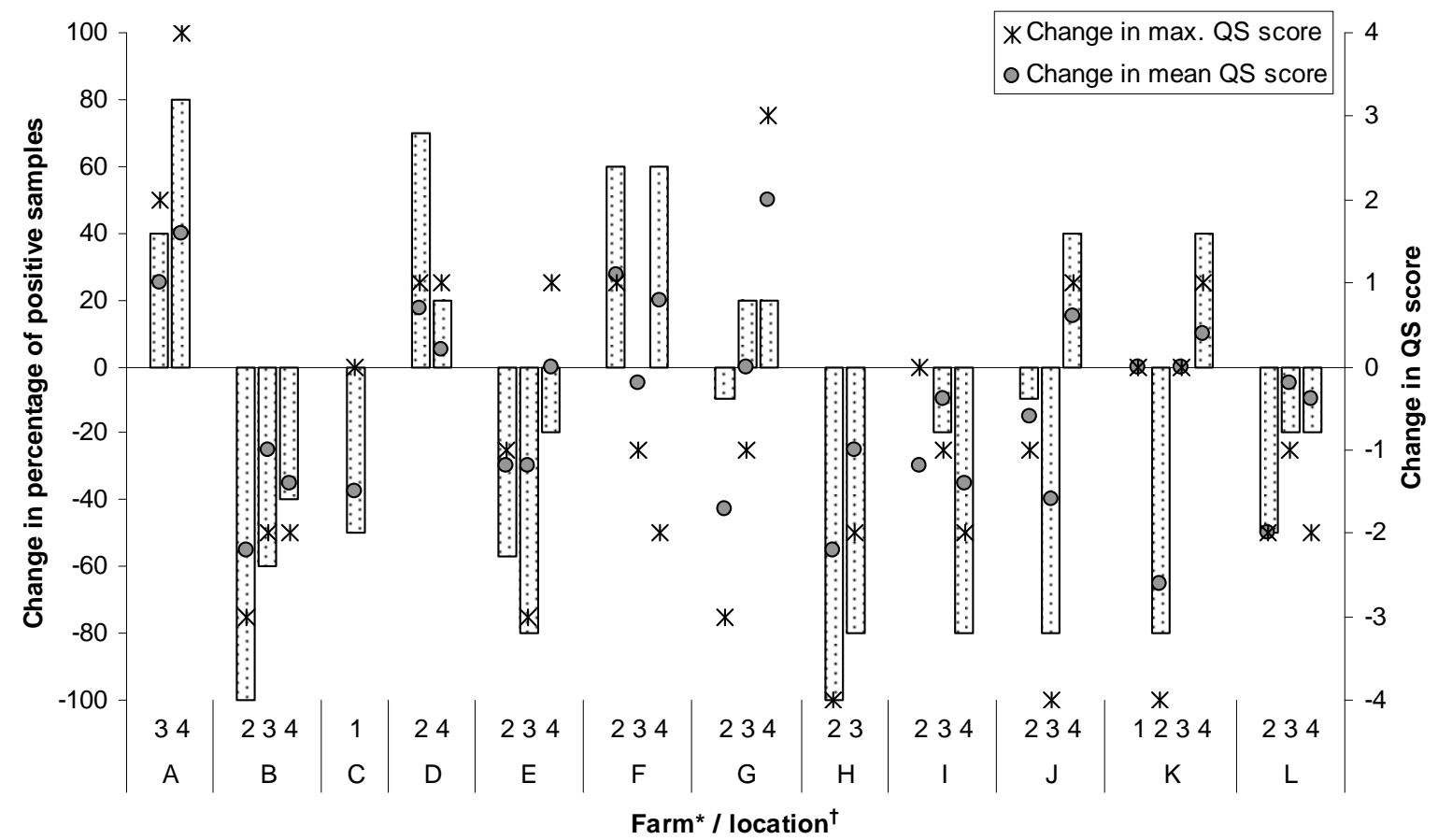

* Farms are lettered as shown in Table 1.

$\dagger$ ‘1': Faeces / droppings boards. '2': Floor spillage / swabs. '3’: Egg belt swabs. '4': Feeder swabs. 